\title{
Analysis on the effect of the various factors on immunoglobulin $G$ in goat colostrum
}

\author{
Xiaoqing Shao ${ }^{1}$, Ming Cheng ${ }^{2}$, Xiaoning Zhang ${ }^{1}$, Cunfang Wang ${ }^{1 *}$, Hua Jiang ${ }^{1 *}$ \\ ${ }^{1}$ College of Food Science and Engineering, Qilu University of Technology (Shandong Academy of Sciences), Jinan, China \\ ${ }^{2}$ Qingdao Institute of Animal Husbandry and Veterinary Medicine, Qingdao, China
}

\begin{abstract}
The present study aimed to determinate the content of immunoglobulin G (IgG) in goat colostrum and the effected factors were discussed by single radial immunodiffusion. The results showed that the highest level of IgG was detected in the first day after partum, and decreased quickly over the length of the lactation period. No significant effect on $\operatorname{IgG}$ was seen with different ways of thawing and the different freezing time. $\operatorname{IgG}$ was almost completely lost at $85^{\circ} \mathrm{C}$ for $2 \mathrm{~min}$. The maximum value of $\operatorname{IgG}$ was observed at $\mathrm{pH} 6.5$, and it reduced significantly when the pressure was higher than $500 \mathrm{MPa}$, and decreased with the increase of the concentrations of citric acid and $\mathrm{Ca}^{2+}$.
\end{abstract}

\section{Introduction}

As a kind of potential alternative of human milk source, goat milk is one of the most important nutritional food in the world, playing an important role in human daily life [1]. Goat milk is of high levels of biologically active proteins, such as immunoglobulin, lactoferrin, EGF, SOD. The immunoglobulins and oligosaccharides in the milk of humans and other mammals provide a significant amount of protection to the recipient.

Numerous factors, such as lactation period, parity, nutrition and genetic selection are known to impact colostrum immunoglobulin concentration [2]. IgG concentration values were reported only in a few studies conducted on a few animals from one breed $[3,4]$. The immune quality of the colostrum in goat milk has been poorly explored and variation factors have neither been evaluated. So the objective of this study was to determine the $\mathrm{IgG}$ concentration of colostrum during the first seven days postpartum and to evaluate the effects of freezing time, different thawing methods, temperature, and different $\mathrm{pH}$ values, high-pressure processing, citric acid concentration, and calcium ion concentration on the concentration and activity of $\mathrm{IgG}$ in goat colostrum in order to provide theoretical references for industry in the utilization of goat colostrum.

\section{Materials and methods}

\subsection{Collection and preparation of goat milk}

Thirty samples goats were randomly selected from the Three Xi Goat Farm in Tai' an City (N35 $52^{\prime}$, E116 $\left.50^{\prime}\right)$,
Shandong province, China. The colostrum samples $(n=7 * 30)$ were collected from the 1 st to 7 th lactation day after parturition ( $7 \mathrm{~d}$ of lactation and once a day). Each sample was divided into several aliquots and transported to lab by cold chain.

\subsection{Single radial immunodiffusion}

The active IgG concentration was determined by single radial immunodiffusion according to Hadorn et al with some modifications [5]. A series of agarose plates were prepared in which the rabbit anti-goat antiserum was diluted 1:2, 1:4, 1:8, 1:16, and 1:32 (Sigma-Aldrich, St. Louis, MO, USA). Then, commercial standard goat IgG (Santa Cruz Biotechnology, Inc., Dallas, TX, USA) was dissolved in PBS to a series of standard solutions (40, 20, 10,5 , and $2.5 \mathrm{mg} / 100 \mathrm{~mL}$ ) on every immunodiffusion well in the agarose to generate a standard curve, as shown in Figure 1. Subsequently goat milk colostrum were treated by the different thawing temperature, heating temperature, $\mathrm{pH}$, and the effect of various factors on $\mathrm{IgG}$ were analyzed respectively.

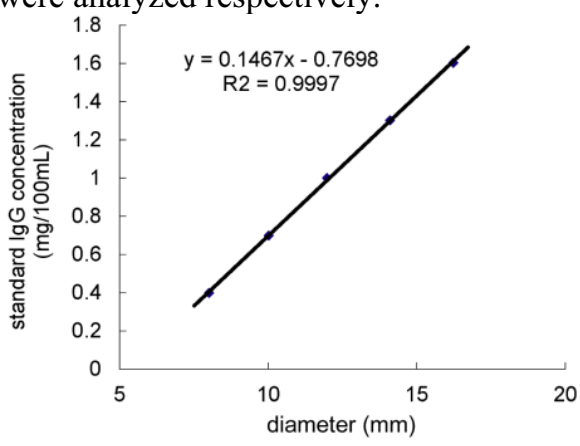

Figure 1. The logarithmic plot of standard goat IgG concentration

\footnotetext{
* Corresponding authors: Cunfang Wang, cunfangwang@163.com and Hua Jiang, 4279833@qq.com
} 


\subsection{Statistical analysis}

All data were presented as means of at least three independent determinations \pm standard deviation (SD). Statistical evaluation was performed by using one-way analysis of variance (ANOVA) of the SPSS 19.0 Statistics program and Fisher's test with a significance level of $\mathrm{P}<0.05$ (in small letter) and very significance level of $\mathrm{P}<0.01$ (in capital letter).

\section{Results and discussion}

\subsection{Changes of IgG from partum to 7 days postpartum}

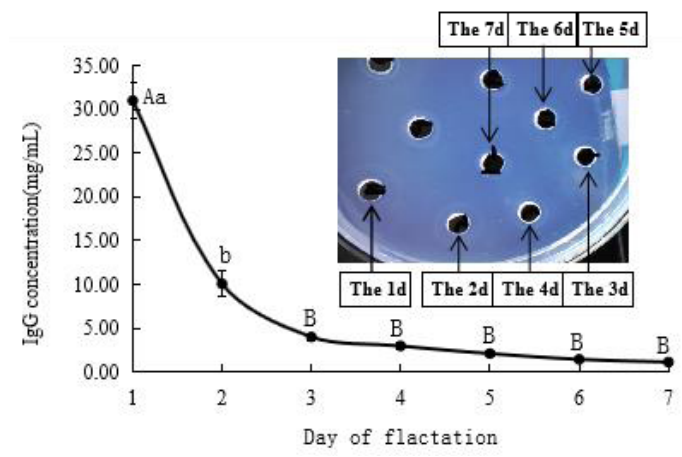

Figure 2. IgG change from partum to 7 days postpartum

The concentration of $\mathrm{IgG}$ in goat colostrum were observed from 1 to $7 \mathrm{~d}$ postpartum, decreased significantly with prolonged lactation (Figure 2). $\operatorname{IgG}$ concentration in milking from 1 to 2 day was significantly higher than that measured from other days of milking during the total 7 days. The results are similar to those previous reported that the $\operatorname{IgG}$ content of the milk in the first 7 days after the milk production[6].

\subsection{Analysis on the effect of storage time and thawing method on IgG}

As shown in Figure 3, the $\operatorname{IgG}$ concentrations showed a slow decline with the increasing of the freezing time for goat colostrum. Compared with the first 45-day preservation, there was significant difference for the 60-day and extremely significant difference for the 75-day and 90-day. In conclusion, after 3 months of preservation at refrigeration temperatures of $-20^{\circ} \mathrm{C}, \operatorname{IgG}$ levels diminished by $10.42 \%$, and the colostrum was still usable for new-born kids, although where possible it would be desirable to store colostrum for no longer than 45 days after collection. This was consistent with the finding that effects were observed within storage room at temperature of $4^{\circ} \mathrm{C}$ for 3 months, and try not more than a month as much as possible [7].

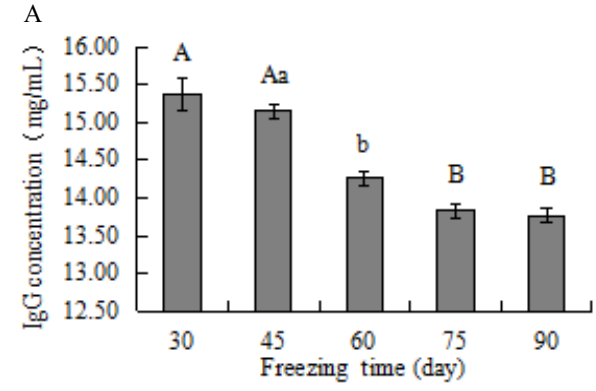

Figure 3. Changes of $\mathrm{IgG}$ with freezing time on

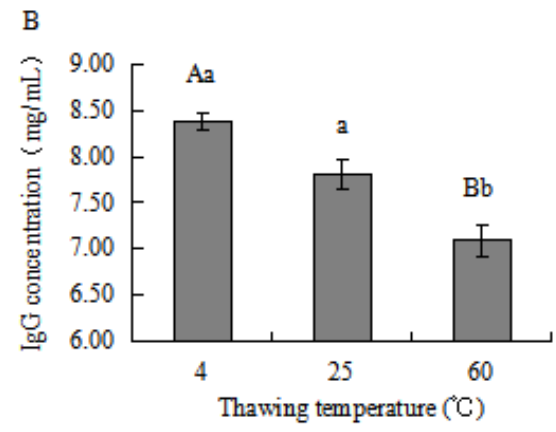

Figure 4. Changes of IgG with the thawing temperature

Figure 4 showed that the $\mathrm{IgG}$ concentration in goat colostrum thawed in $60^{\circ} \mathrm{C}$ water bath was significantly lower than that thawed at $25^{\circ} \mathrm{C}$ and $4^{\circ} \mathrm{C}(\mathrm{p}<0.05)$, but no significantly difference between $25^{\circ} \mathrm{C}$ and at $4^{\circ} \mathrm{C}$. Argüello et al. ascertained that different thawing methods: refrigeration $\left(4{ }^{\circ} \mathrm{C}\right)$, room temperature $\left(27{ }^{\circ} \mathrm{C}\right)$, microwave $\left(55{ }^{\circ} \mathrm{C}\right)$ and hot water $\left(60^{\circ} \mathrm{C}\right)$ made no difference on IgG concentration. But, repeated freezing and thawing can reduce $\operatorname{IgG}$ concentration [7]. It is generally known that thawing at $4^{\circ} \mathrm{C}$ takes time, so the room temperature $\left(25^{\circ} \mathrm{C}\right)$ was the preferred thawing method for the freezing goat milk.

\subsection{Analysis on the effect of heating temperature on IgG}

As Figure 5 showed, the concentration of $\operatorname{IgG}$ has a significant decline as temperature was increased. When the goat colostrum was heated at $65^{\circ} \mathrm{C}$, the concentration of IgG was found to be invariable, in general, regardless of treatment duration. The trends are in agreement with those of McMartin et al. with conditions of $63^{\circ} \mathrm{C}$ for 120 min and of Tyler et al. with conditions of $63^{\circ} \mathrm{C}$ for 30 min, IgG was still stable, used for pasteurization processing $[8,9]$. 


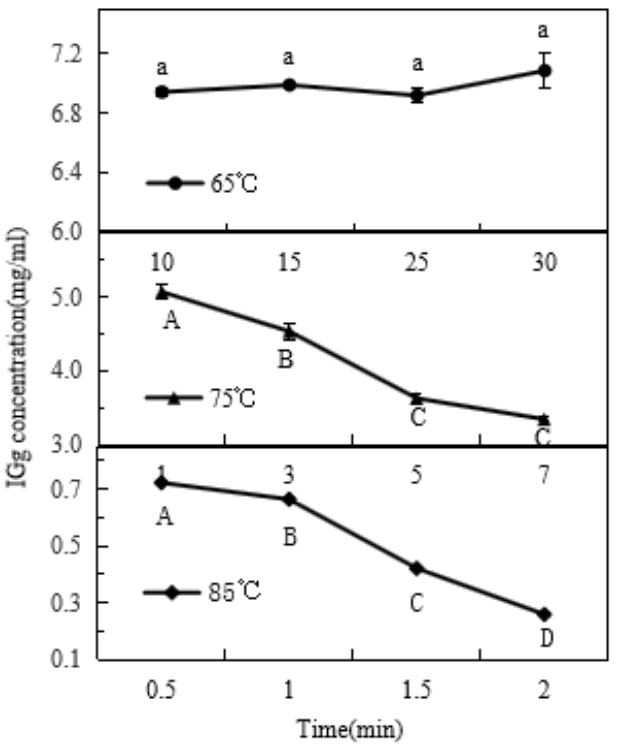

Figure 5. Changes of IgG with heating temperature

But when the goat colostrum was heated at $75^{\circ} \mathrm{C}$ for 5 min, there was a significant decrease in IgG concentration $(p<0.01)$. Heat treatment at a temperature higher than $72^{\circ} \mathrm{C}$ caused a loss in immune activity and a change in the secondary structure of bovine $\operatorname{IgG}$ at neutral $\mathrm{pH}[10]$. The $\operatorname{IgG}$ was almost completely inactivated after heated at $85^{\circ} \mathrm{C}$ for $2 \mathrm{~min}$. Ustunol et al. had found that IgG was the most stable immunoglobulin at $70^{\circ} \mathrm{C}$ and that there was a sharp decrease in the activity of $\operatorname{IgG}$ within the first $5 \mathrm{~min}$ at $85^{\circ} \mathrm{C}$ [11]. These results suggest that pasteurization processes do not necessarily result in complete destruction of $\mathrm{IgG}$, and $\mathrm{IgG}$ in colostrum has good thermal stability at $65^{\circ} \mathrm{C}$.

\subsection{Analysis on the effect of $\mathrm{pH}$ on IgG}

The effect of $\mathrm{pH}$ on the $\operatorname{IgG}$ concentration in goat colostrum was displayed in Figure 6. The maximum IgG level was observed at $\mathrm{pH}$ 6.5. At $\mathrm{pH}$ levels less than 6.5, the concentration of active $\operatorname{IgG}$ decreased by approximately $20 \%$ of the maximum value at $\mathrm{pH} 4.0$. At $\mathrm{pH}$ more than 7.5, in an alkaline environment, IgG levels significantly dropped and were only $60 \%$ of the maximum when the $\mathrm{pH}$ increased to $\mathrm{pH} 9.5$. No IgG activity was detected for a $\mathrm{pH}$ lower than 4.0 or higher than 10.0 [12]. When the $\mathrm{pH}$ value is greater than 12 , the activity of immunoglobulin $\mathrm{G}$ in goose drops rapidly and increases the infection rate of GPV virus [13]. Therefore, $\mathrm{IgG}$ had poor stability in both strong acids and strong bases.

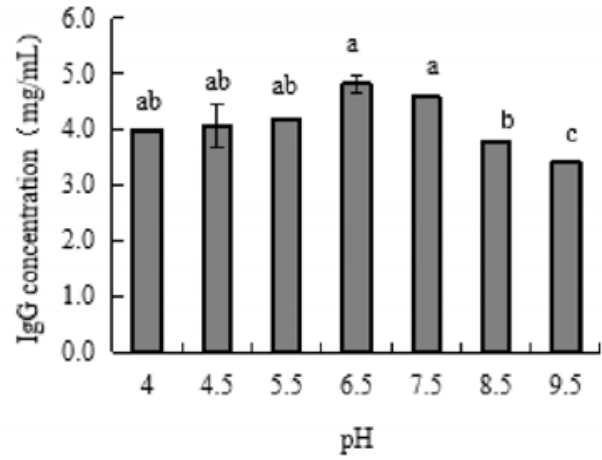

Figure 6. Changes of $\mathrm{IgG}$ with $\mathrm{pH}$

\subsection{Analysis on the effect of ultra-high pressure treatment on IgG}

Figure 7 showed that $\operatorname{IgG}$ concentraton began to decline rapidly during the first $15 \mathrm{~min}$ for all pressure treatment conditions. A remarkably significant reduction was observed as the pressure treatments increased from 200 to $500 \mathrm{MPa}$ at each time point. But, with $500 \mathrm{MPa}$ treatment for $20 \mathrm{~min}$, IgG levels had dropped to about $70 \%$ of those treated for $10 \mathrm{~min}$, which were similar to previous report that treatment of $500 \mathrm{MPa}$ caused significant losses of IgG in goat colostrum [14, 15].

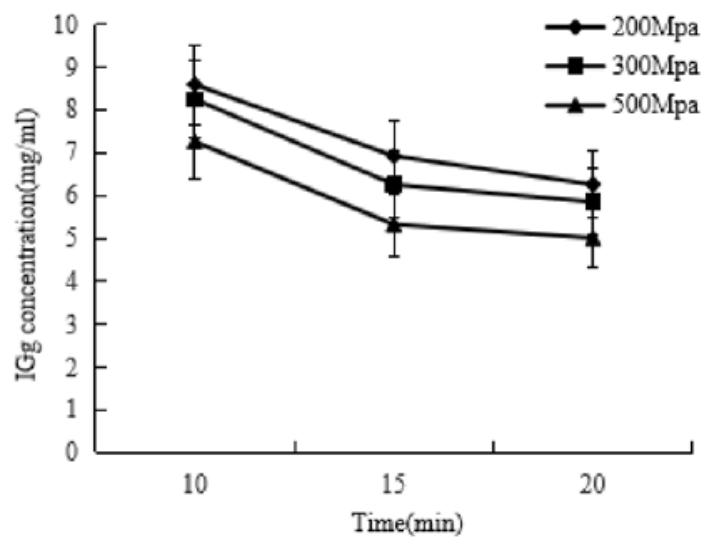

Figure 7. Changes of $\operatorname{IgG}$ with ultra-high pressure

\subsection{Analysis on the effect of citric acid and calcium salts concentration on IgG}

As Figure 8 displayed, with increasing concentrations of citric acid, the concentration of IgG reduced dramatically $(p<0.05)$. The highest concentration of citric acid significantly reduced the $\mathrm{pH}$ value of milk samples to about $\mathrm{pH} 3.5$ and these results are consistent with the previous studies [16] demonstrating that the stability of $\mathrm{IgG}$ in colostrum is greatly reduced under strong acidic conditions. 


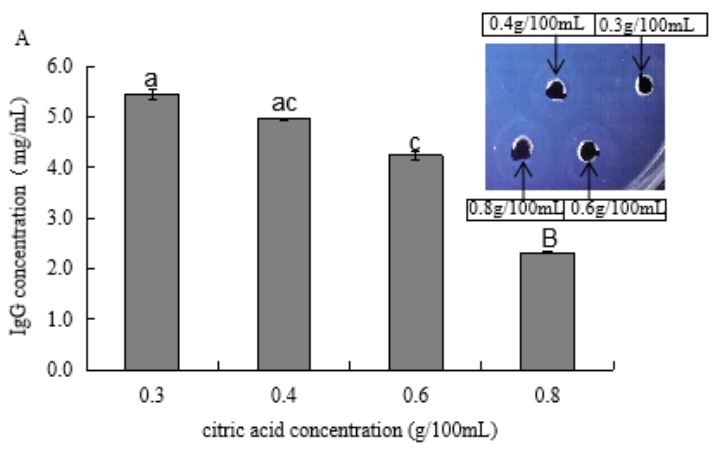

Figure 8. Changes of IgG with the concentration of citric acid

With the concentration of calcium ions increasing, IgG concentration was found to decrease significantly (Figure 9). No IgG was measureable when the concentration of calcium ions was higher than $1.0 \mathrm{~g} / \mathrm{ml}$. In general, the more calcium that was added to the colostrum, the worse the stability of the goat colostrum.

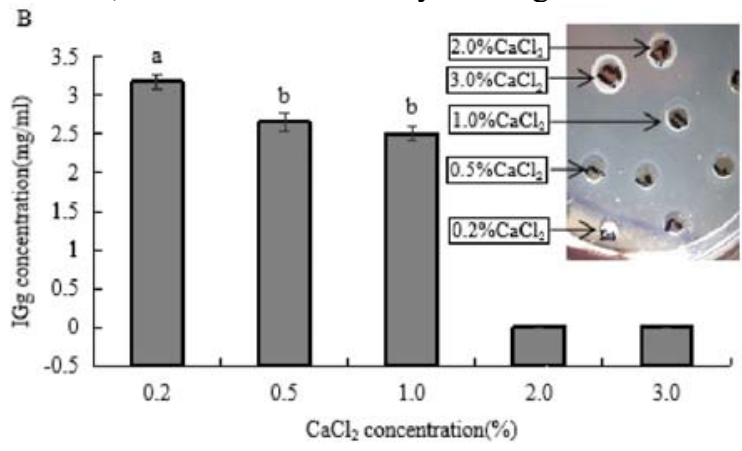

Figure 9. Changes of $\mathrm{IgG}$ with the concentration of $\mathrm{Ca}^{2+}$

\section{Conclusion}

In conclusion, the freezing of goat colostrum was a good method of IgG preservation for the first 45 days, and room temperature was of the preferred thawing method for the freezing goat milk. At $\mathrm{pH} 6.5$, the maximum of $\mathrm{IgG}$ concentration in goat milk was observed. The IgG concentrations decreased significantly with prolonged lactation, and increasing of the temperature, citric acid, calcium salts concentration, and ultra-high pressure. In this paper, we determine the optimal conditions to maintain maximum immunoglobulin activity for goat milk, and the key parameters controlling the stability of immunoglobulin with high activity can be used in practice for goat milk products processing.

\section{Acknowledgments}

This work was supported by the Key Research and Development Program of Shandong province (2019YYSP025), Shandong Major Agricultural Technology Innovation Project (SD2019ZZ006) and National College Student Innovation and Entrepreneurship Training Program (201910431002)

\section{References}

1. SELVAGGI M, LAUDADIO V, DARIO C, et al. Major proteins in goat milk: an updated overview on genetic variability $[\mathrm{J}]$. Molecular biology reports, 2014, 41(2): 1035-48.

2. CASTRO N. From goat colostrum to milk: physical, chemical, and immune evolution from partum to 90 days postpartum [J]. Journal of Dairy Science, 2014, 97(1): 10-6.

3. HEDDLE R, ROWLEY D. Dog immunoglobulins. I. immunochemical characterization of dog serum, parotid saliva, colostrum, milk and small bowel fluid [J]. Immunology, 1975, 29(1): 185.

4. SCH FER-SOMI S, ALI AKSOY O, PATZL M, et al. The Activity of Matrix Metalloproteinase-2 and-9 in Serum of Pregnant and Non-Pregnant Bitches [J]. Reproduction in domestic animals, 2005, 40(1): 46-50

5. HADORN U, BLUM J W. Effects of feeding colostrum, glucose or water on the first day of life on plasma immunoglobulin $G$ concentrations and gamma-glutamyltransferase activities in calves $[\mathrm{J}]$. Zentralblatt Für Veterinärmedizin Reihe A, 1997, 44(9-10): 531-7.

6. LEVIEUX D, MORGAN F, GENEIX N, et al. Caprine immunoglobulin G, $\beta$-lactoglobulin, $\alpha$-lactalbumin and serum albumin in colostrum and milk during the early post partum period [J]. Journal of Dairy Research, 2002, 69(3): 391-9.

7. ARG ELLO A, CASTRO N, CAPOTE J. Effects of refrigeration, freezing-thawing and pasteurization on IgG goat colostrum preservation [J]. Small Ruminant Research, 2003, 2(2): 135-9.

8. MCMARTIN S, ., GODDEN S, ., METZGER L, ., et al. Heat Treatment of Bovine Colostrum. I: Effects of Temperature on Viscosity and Immunoglobulin G Level [J]. Journal of Dairy Science, 2006, 89(6): 2110-8.

9. TYLER J W, LAKRITZ J, HOSTETLER D E, et al. Effect of pasteurization at 76 and $63{ }^{\circ} \mathrm{C}$ on the absorption of colostral IgG in calves [J]. Journal of Dairy Research, 2000, 67(4): 619-23.

10. SI-QUAN L, BOMSER J A, Q HOWARD Z. Effects of Pulsed Electric Fields and Heat Treatment on Stability and Secondary Structure of Bovine Immunoglobulin $G[J]$. Journal of Agricultural \& Food Chemistry, 2005, 53(3): págs. 663-70.

11. USTUNOL Z, SYPIEN C. Heat Stability of Bovine Milk Immunoglobulins and Their Ability to Bind Lactococci as Determined by an ELISA [J]. Journal of Food Science, 1997, 62(6): 1218-22.

12. C.-C. C, H.-M. C. Effect of thermal protectants on the stability of bovine milk immunoglobulin $\mathrm{G}[\mathrm{J}]$. Journal of Agricultural \& Food Chemistry, 1998, 46(9): 3570-6.

13. ZHU XIN-CHAN S Y-H, ZHU FENG-WEI, YANG 
LI-JIN. Study on the Molecular Variability of Immunoglobulin $\mathrm{IgG} / \mathrm{IgM}$ from Goslings InfectedGoose Parvovirus [J]. ACTA AGRICULTURAE BOREALI-SINICA, 2015, 30(1): 42-53.

14. TRUJILlO A J, CASTRO N, ., QUEVEDO J M, et al. Effect of heat and high-pressure treatments on microbiological quality and immunoglobulin $G$ stability of caprine colostrum [J]. Journal of Dairy Science, 2007, 90(2): 833-9.

15. SI-QUAN L, ZHANG H Q, BALASUBRAMANIAM V M, et al. Comparison of effects of high-pressure processing and heat treatment on immunoactivity of bovine milk immunoglobulin $G$ in enriched soymilk under equivalent microbial inactivation levels [J]. Journal of Agricultural \& Food Chemistry, 2006, 54(3): 739-46.

16. SCATAMBURLO $\mathrm{T} \mathrm{M}$, YAMAZI A K, CAVICCHIOLI V Q, et al. Spoilage potential of Pseudomonas species isolated from goat milk [J]. Journal of Dairy Science, 2015, 98(2): 759-64. 